Received: 2019/12/12, Revised: 2019/12/18, Accepted: 2019/12/18, Published: 2019/12/31 @2019 Sung-Woo Kim et al.; License Journal of Exercise Nutition and Biochemistry. This is an open access article distributed under the terms of the creative commons attribution license (http://creativecommons.org/licenses/by/2.0), which permits unrestricted use, distribution, and reproduction in any medium, provided the orginal work is properly cited. ${ }^{*}$ Corresponding author : Jong-Kook Song, Ph.D.

Department of Taekwondo, College of Physical Education, Kyung Hee University, 1732 Deokyoungdaero, Giheung-gu, Yongin-si, Gyeonggi-do 17014, Republic of Korea

Tel: +82-31-201-2708

E-mail: jksong@khu.ac.kr

@2019 The Korean Society for Exercise Nutrition

[Purpose] The study aimed to determine the effects of bone-specific physical activity on body composition, bone mineral density (BMD), and health-related physical fitness in middle-aged women.

[Methods] One hundred eighty-six middle-aged women aged 31-49 years participated in this study. The subjects were divided into tertile groups according to the level of physical activity (low-score group, $n=62$; middle-score group, $n=62$; high-score group, $n=62$ ). Bone-specific physical activity participation was assessed using the bone-specific physical activity questionnaire. Body composition and BMD were measured using dual-energy $\mathrm{X}$-ray absorptiometry. Health-related physical fitness test included isometric muscle strength (grip strength), muscular endurance (sit-ups) flexibility (sit and reach), and cardiorespiratory fitness (maximal oxygen uptake [ $\left.\mathrm{VO}_{2 m a x}\right]$ ).

[Results] The high-score group had a significantly higher fat-free mass $(p=045$, partial eta-squared value $\left.\left[\eta_{\mathrm{p}}{ }^{2}\right]=.033\right)$ than the middle- and low-score groups, whereas the high-score group had significantly lower percent body fat $\left(p=.005, \eta_{p}^{2}=.056\right)$ than the other two groups. Whole-body BMD ( $p=034, \eta_{p}{ }^{2}=036$ ) and lumbar BMD ( $\left.p=.003, \eta_{p}^{2}=.060\right)$ were significantly higher in the high-score group than in the low-score group. The high-score group performed significantly better for grip strength $\left(p=.0001, \eta_{p}^{2}=.101\right)$, sit-ups ( $p=.0001$, $\left.\eta_{p}{ }^{2}=.108\right)$, and $\mathrm{VO}_{2 \max }\left(p=.0001, \eta_{p}{ }^{2}=.092\right)$ than the other two groups.

[Conclusion] The present study suggests that bone-specific physical activity could be useful in improving body composition, $\mathrm{BMD}$, and health-related physical fitness in middle-aged women, significantly enhancing their BMD and health conditions.

[Key words] bone-specific physical activity, body composition, bone mineral density, health-related physical fitness, middle-aged women

\section{Effects of bone-specific physical activity on body composition, bone mineral density, and health-related physical fitness in middle-aged women}

\author{
Sung-Woo Kim ${ }^{1}$ / Sung-Woo Jung ${ }^{2}$ / Myong-Won Seo ${ }^{2}$ / \\ Hun-Young Park ${ }^{1,3} /$ Jong-Kook Song $2^{*}$
}

1. Physical Activity and Performance Institute (PAPI), Konkuk University, Seoul, Republic of Korea 2. Department of Taekwondo, College of Physical Education, Kyung Hee University, Yongin, Republic of Korea 3. Department of Sports Medicine and Science, Konkuk University, Seoul, Republic of Korea

\section{INTRODUCTION}

The Lancet Physical Activity Series Working Group reported that approximately $31 \%$ of adults worldwide have insufficient physical activity (PA), resulting in several chronic diseases, such as stroke, osteoporosis, diabetes, and hypertension, which are the major risk factors for mortality ${ }^{1,2}$. Moreover, insufficient PA has a negative impact on cardiovascular diseases, including coronary artery disease and stroke $\mathrm{s}^{3-5}$. Lozano et al. ${ }^{6}$ reported that cardiovascular deaths accounted for $29.6 \%$ of all-cause mortality, which was two times higher than that caused by cancer. Individuals who participate in regular physical activities have a lower risk of being diagnosed with cardiovascular diseases than individuals who are engaged in a sedentary lifestyle ${ }^{7,8}$. It was also revealed that premature mortality could be reduced to approximately $20 \%$ when individuals participate in PA regularly 9 . Unfortunately, $85 \%$ of adults (men and women) do not regularly participate in moderate-to-vigorous PA greater than 150 min per week, and the incidence of being diagnosed with a disease, as a result of insufficient PA, did not decrease over the last 10 years ${ }^{10-12}$. Furthermore, the incidence of metabolic diseases, such as obesity, cardiovascular disease, and type 2 diabetes, is increasing in adults due to insufficient $\mathrm{PA}^{13,14}$. Therefore, middle-aged women need to participate in regular PA because it can not only reduce the risk of disease but also improve health and manage PA levels according to their life cycle.

Body composition consistently changes throughout life, which is caused by various factors such as aging, dietary intake, and PA. Generally, the amount of fat increases but muscle mass and bone mineral density (BMD) decrease with aging ${ }^{15,16}$. Particularly, muscle mass gradually decreases from the late $20 \mathrm{~s}$ with a ratio of $0.4-0.8 \mathrm{~kg}$ per decade ${ }^{17}$. Moreover, premenopausal women's BMD is associated with weight, while it is less associated with fat and more dependent on fatfree mass (FFM) ${ }^{18}$. For women, after reaching $90 \%$ of the peak bone mass at age 18, BMD begins to decrease at a relatively slow rate and rapidly decreases at a rate of $0.5 \%-1 \%$ per year after menopause ${ }^{19-21}$. 
Table 1. Physical characteristics and bone-specific physical activity questionnaire scores by physical activity level

\begin{tabular}{|c|c|c|c|c|c|}
\hline & $\begin{array}{l}\text { Low-score group } \\
\qquad(n=62)\end{array}$ & $\begin{array}{l}\text { Middle-score group } \\
\qquad(\mathrm{n}=62)\end{array}$ & $\begin{array}{l}\text { High-score group } \\
\qquad(n=62)\end{array}$ & $F$-value & Prob $>F$ \\
\hline Age (yrs) & $40.4 \pm 4.06 a$ & $41.1 \pm 4.13 a$ & $39.8 \pm 3.94 a$ & 1.525 & .220 \\
\hline Body height $(\mathrm{cm})$ & $161.1 \pm 4.85 a$ & $160.7 \pm 5.24 a$ & $162.7 \pm 5.08 a$ & 2.802 & .063 \\
\hline Body weight (kg) & $58.8 \pm 8.59 a$ & $58.9 \pm 9.88 a$ & $59.0 \pm 9.02 a$ & .014 & .986 \\
\hline BMI $\left(\mathrm{kg} / \mathrm{m}^{2}\right)$ & $22.6 \pm 3.14 a$ & $22.8 \pm 3.61 \mathrm{a}$ & $22.3 \pm 3.10 a$ & .429 & .652 \\
\hline Current BPAQ score & $0.3 \pm 0.46 a$ & $1.9 \pm 3.12 \mathrm{a}$ & $5.8 \pm 13.93 b$ & 7.368 & .001 \\
\hline $\begin{array}{l}\text { Past BPAQ } \\
\text { score }\end{array}$ & $1.7 \pm 0.79 a$ & $8.7 \pm 5.39 b$ & $37.0 \pm 20.31 \mathrm{c}$ & 146.784 & .0001 \\
\hline $\begin{array}{l}\text { Total BPAQ } \\
\text { score }\end{array}$ & $1.0 \pm 0.44 a$ & $5.3 \pm 2.49 \mathrm{~b}$ & $21.4 \pm 10.66 c$ & 179.732 & .0001 \\
\hline
\end{tabular}

Note. Values are expressed as mean \pm standard deviation.

Different lowercase letters indicate significant differences among the groups $\mathrm{BMI}$, body mass index; BPAQ, bone-specific physical activity questionnaire

Therefore, increasing the peak bone mass and maintaining BMD during adulthood are significantly important. Middle-aged women participate in regular physical activities to maintain high BMDs and minimize bone loss, reducing the risk of fractures and osteoporosis that can occur after menopause.

PA and physical fitness are important factors in promoting health status ${ }^{13}$. According to the previous studies ${ }^{22-24}$, health-related physical health can be affected not only by lifestyle and genetic factors but also by participation in regular PA. Moreover, aging and insufficient PA will lead to a decrease in health-related physical fitness and daily functional impairment ${ }^{25,26}$. The maximal oxygen uptake $\left(\mathrm{VO}_{2 \mathrm{max}}\right)$, which is an index of cardiovascular endurance in the health-related physical fitness, is reduced by approximately $3 \%-6 \%$ with aging ${ }^{27}$. High levels of cardiopulmonary endurance and muscle mass maintained from adulthood can reduce the incidence of cardiovascular and metabolic diseases such as hypertension and diabetes $^{28,29}$. Additionally, physical fitness, which is achieved through regular PA, also exhibits a positive impact on life expectancy by reducing mortality from cardiovascular diseases $^{30}$. Thus, health-related physical fitness is an indirect health indicator of the body, and it is significantly necessary to manage it continuously by participating in regular PA.

The PA research tools and methods used in the previous studies did not examine the type of PA that may impact bone health. However, the bone-specific physical activity questionnaire (BPAQ), which considers the type of PA that could directly impact bone health, has recently been developed and used in some previous studies ${ }^{31-35}$. Therefore, our study aimed to determine the effects of bone-specific PA on body composition, BMD, and health-related physical fitness in middle-aged women.

\section{METHODS}

\section{Participants}

A total of 205 middle-aged women aged 31-49 years were randomly selected. Based on their past medical history, these women had no medical problems. However, 19 participants were excluded due to personal reasons. Overall, this study included 186 middle-aged women. According to the PA level estimated using the BPAQ, participants were divided into tertile groups (low-score group, $n=62$; middle-score group, $n=62$; high-score group, $n=62)^{36}$. The characteristics of the participants are shown in Table 1 .

\section{Study design}

The participants from Gyeonggi-do Province were recruited from January to February 2018, and they were randomly sampled through posters and flyers. Before the study, the objectives, procedures, advantages, and potential disadvantages of this study were explained to all participants. This study was approved by the Institutional Review Board of Kyung Hee University (KHSIRB-17-048). Each participant provided written informed consent. On the testing day, body composition (FFM, fat mass [FM], and percent body fat), BMD (whole-body, lumbar, femur, and forearm region), health-related physical fitness (grip strength [GS], sit-ups [SU], sit and reach [SAR], and $\mathrm{VO}_{2 \max }$ ), and BPAQ (current BPAQ [cBPAQ], past BPAQ [pBPAQ], and total BPAQ [tBPAQ]) were measured between 9:00 and 11:00 AM.

\section{Measurements}

\section{Body composition and bone mineral density}

The body height and weight were measured, and body mass index was calculated by dividing the body weight $(\mathrm{kg})$ by the square of body height $\left(\mathrm{m}^{2}\right)$. Body composition and BMD were measured using dual-energy X-ray absorptiometry, with a Hologic QDR 4500W bone densitometer (Hologic, Marlborough, USA). Body compositions, including FM, percent body fat, and FFM, were analyzed. All the participants were scanned at four different sites of the BMD (e.g., whole-body, lumbar, femur, and forearm region).

\section{Health-related physical fitness}

Health-related physical fitness test included isometric muscle strength (GS), muscular endurance (SU), flexibility (SAR), and cardiorespiratory fitness $\left(\mathrm{VO}_{2} \max \right)$. The graded exercise stress test (GXT) using the Bruce protocol was performed to measure the $\mathrm{VO}_{2 \max }$. Oxygen uptake was measured using a Quark b2 (COSMED, Rome, Italy). All participants started walking at $1.7 \mathrm{mph}$ with a $10 \%$ gradient. The speed was increased to $0.8-0.9 \mathrm{mph}$ at 3-min intervals, 
Table 2. Comparison of body composition among the three groups

\begin{tabular}{|c|c|c|c|c|c|c|}
\hline & $\begin{array}{l}\text { Low-score group } \\
\qquad(95 \% \mathrm{Cl})\end{array}$ & $\begin{array}{l}\text { Middle-score group } \\
\qquad(95 \% \mathrm{Cl})\end{array}$ & $\begin{array}{l}\text { High-score group } \\
(95 \% \mathrm{Cl})\end{array}$ & $F$-value & Prob $>F$ & $\eta_{p}^{2}$ \\
\hline Fat mass $(\mathrm{kg})$ & $\begin{array}{r}18.8 \pm 5.56 a \\
(17.3-20.2)\end{array}$ & $\begin{array}{r}18.8 \pm 6.02 a \\
(17.4-20.4)\end{array}$ & $\begin{array}{r}17.2 \pm 5.94 a \\
(15.8-18.8)\end{array}$ & 1.566 & .212 & .017 \\
\hline Fat-free mass (kg) & $\begin{array}{l}37.0 \pm 4.07 a \\
(36.0-38.2)\end{array}$ & $\begin{array}{l}36.9 \pm 4.92 a \\
(35.8-38.2)\end{array}$ & $\begin{array}{l}38.8 \pm 4.61 b \\
(37.6-39.9)\end{array}$ & 3.153 & .045 & .033 \\
\hline Percent body fat (\%) & $\begin{array}{l}31.9 \pm 5.43 a \\
(30.5-33.3)\end{array}$ & $\begin{array}{l}32.0 \pm 5.89 a \\
(30.6-33.4)\end{array}$ & $\begin{array}{l}28.9 \pm 6.39 b \\
(27.4-30.7)\end{array}$ & 5.427 & .005 & .056 \\
\hline
\end{tabular}

Note. Values are expressed as mean \pm standard deviation.

Different lowercase letters indicate significant differences among the groups

$95 \% \mathrm{Cl}, 95 \%$ confidence interval

Table 3. Comparison of bone mineral density among the three groups

\begin{tabular}{|c|c|c|c|c|c|c|}
\hline & $\begin{array}{l}\text { Low-score group } \\
\qquad(95 \% \mathrm{Cl})\end{array}$ & $\begin{array}{l}\text { Middle-score group } \\
\qquad(95 \% \mathrm{Cl})\end{array}$ & $\begin{array}{l}\text { High-score group } \\
\qquad(95 \% \mathrm{Cl})\end{array}$ & $F$-value & Prob $>F$ & $\eta_{p}^{2}$ \\
\hline $\begin{array}{l}\text { Whole-body } \\
\text { BMD }\left(\mathrm{g} / \mathrm{cm}^{2}\right)\end{array}$ & $\begin{array}{r}1.113 \pm 0.070 \mathrm{a} \\
(1.096-1.132)\end{array}$ & $\begin{array}{c}1.121 \pm 0.072 \mathrm{ab} \\
(1.101-1.139)\end{array}$ & $\begin{array}{l}1.148 \pm 0.087 b \\
(1.128-1.170)\end{array}$ & 3.446 & .034 & .036 \\
\hline $\begin{array}{l}\text { Femur BMD } \\
\left(\mathrm{g} / \mathrm{cm}^{2}\right)\end{array}$ & $\begin{array}{l}0.864 \pm 0.104 a \\
(0.840-0.890)\end{array}$ & $\begin{array}{l}0.860 \pm 0.100 a \\
(0.835-0.885)\end{array}$ & $\begin{array}{l}0.890 \pm 0.098 a \\
(0.867-0.915)\end{array}$ & 1.609 & .203 & .017 \\
\hline $\begin{array}{l}\text { Lumbar BMD } \\
\qquad\left(\mathrm{g} / \mathrm{cm}^{2}\right)\end{array}$ & $\begin{array}{l}0.993 \pm 0.109 a \\
(0.965-1.022)\end{array}$ & $\begin{array}{l}1.004 \pm 0.106 a \\
(0.978-1.033)\end{array}$ & $\begin{array}{l}1.057 \pm 0.114 b \\
(1.030-1.086)\end{array}$ & 5.881 & .003 & .060 \\
\hline $\begin{array}{l}\text { Forearm BMD } \\
\qquad\left(\mathrm{g} / \mathrm{cm}^{2}\right)\end{array}$ & $\begin{array}{l}0.562 \pm 0.036 a \\
(0.553-0.571)\end{array}$ & $\begin{array}{l}0.561 \pm 0.032 a \\
(0.553-0.569)\end{array}$ & $\begin{array}{l}0.563 \pm 0.034 a \\
(0.554-0.572)\end{array}$ & .053 & .949 & .001 \\
\hline
\end{tabular}

Note. Values are expressed as mean \pm standard deviation.

Different lowercase letters indicate significant differences among the groups

$95 \% \mathrm{Cl}, 95 \%$ confidence interval; BMD, bone mineral density

and the incline was increased by $2 \%$ with each stage. The GXT was performed on a treadmill (Series 2000, Marquette Electronics, Wisconsin, USA). Maximal heart rate (HRmax) was measured using a heart rate monitor (Polar RS400, Polar Electro Oy, Kempele, Finland). VO2max was defined as follows. The participants should meet three out of the following four criteria: (1) oxygen uptake alteration should not exceed $2.1 \mathrm{ml} / \mathrm{kg} / \mathrm{min}$ ( $\mathrm{VO}_{2}$ plateau), (2) heart rate should not increase regardless if the stage was increased, (3) the ratings of perceived exertion (RPE) should be $>17$ (RPE of 6-20), and (4) RER should be over $1.1^{37}$.

\section{Bone-specific physical activity questionnaire}

The BPAQ assessment instrument aims to evaluate the PA level that exerts a mechanical load on the bone ${ }^{31}$. Participants were asked to complete the two independent sections of the BPAQ, that is, the pBPAQ (previous PA level from birth to 12 months) and the cBPAQ (previous 12-month period PA level). The online Microsoft Visual Basic program was used to generate the $\mathrm{pBPAQ}, \mathrm{cBPAQ}$, and tBPAQ scores.

\section{Statistical analysis}

The power test was performed using G*Power 3.1.9.2 (Franz Faul, University of Kiel, Kiel, Germany) with an effect size of 0.25 , a significance level of $0.05(\alpha=0.05)$, and a power of 0.8 for all statistical tests. $G^{*}$ Power showed that 159 participants had sufficient power for this study.

Statistical analyses were performed using the Statistical Analysis System (SAS) software version 9.4 (SAS Institute, Cary, NC, USA). The mean, standard deviation, and 95\% confidence interval were calculated. One-way analysis of variance was used to determine the differences among the three groups on the dependent variables and was followed by Duncan's post-hoc multiple range test. The effect size was computed as partial eta-squared values $\left(\eta_{\mathrm{p}}{ }^{2} ;\right.$ small, $\geq .01$; medium, $\geq .06$; large, $\geq .14$ ). The statistical significance level was set at 0.05 .

\section{RESULTS}

\section{Body composition}

Table 2 indicates the difference of body composition in middle-aged women by bone-specific PA level. There were no significant differences in $\mathrm{FM}\left(F=1.566, p=.212, \eta_{\mathrm{p}}{ }^{2}\right.$ $=.017)$ among the three groups. However, significant differences were observed on FFM $\left(F=3.153, \mathrm{p}=.045, \eta_{\mathrm{p}}{ }^{2}=.033\right)$ and percent body fat $\left(F=5.427, p=.005, \eta_{\mathrm{p}}{ }^{2}=.056\right)$ among the three groups. The high-score group $(38.8 \pm 4.61 \mathrm{~kg})$ had significantly higher FFM than the middle- $(36.9 \pm 4.92 \mathrm{~kg})$ and low-score groups $(37.0 \pm 4.07 \mathrm{~kg})$. On the contrary, the high-score group $(28.9 \pm 6.39 \%)$ had significantly lower percent body fat than the other two groups (middle-score group, 32.0 $\pm 5.89 \%$; low-score group, $31.9 \pm 5.43 \%$ ).

\section{Bone mineral density}

Table 3 shows the significant differences in wholebody BMD $\left(F=3.446, p=.034, \eta_{\mathrm{p}}{ }^{2}=.036\right)$ and lumbar BMD $\left(F=5.881, p=.003, \eta_{\mathrm{p}}{ }^{2}=.060\right)$ among the three groups. However, significant differences were not observed for femur BMD $\left(F=1.609, p=.203, \eta_{\mathrm{p}}{ }^{2}=.017\right)$ and forearm $\operatorname{BMD}\left(F=.053, p=.949, \eta_{\mathrm{p}}{ }^{2}=.001\right)$ among the three groups. The high-score group $\left(1.148 \pm 0.087 \mathrm{~g} / \mathrm{cm}^{2}\right)$ had significantly higher whole-body BMD than the low-score group $\left(1.113 \pm 0.070 \mathrm{~g} / \mathrm{cm}^{2}\right)$. Moreover, the high-score group $\left(1.057 \pm 0.114 \mathrm{~g} / \mathrm{cm}^{2}\right)$ had significantly higher lumbar BMD than both the middle- $\left(1.004 \pm 0.106 \mathrm{~g} / \mathrm{cm}^{2}\right)$ and low-score 
Table 4. Comparison of health-related physical fitness among the three groups

\begin{tabular}{|c|c|c|c|c|c|c|}
\hline & $\begin{array}{l}\text { Low-score group } \\
\qquad(95 \% \mathrm{Cl})\end{array}$ & $\begin{array}{l}\text { Middle-score group } \\
\qquad(95 \% \mathrm{CI})\end{array}$ & $\begin{array}{l}\text { High-score group } \\
(95 \% \mathrm{Cl})\end{array}$ & $F$-value & Prob $>F$ & $\eta_{p^{2}}^{2}$ \\
\hline Sit and reach $(\mathrm{cm})$ & $\begin{array}{l}10.2 \pm 9.43 a \\
(7.7-12.5)\end{array}$ & $\begin{array}{l}10.5 \pm 9.20 \mathrm{a} \\
(8.3-12.8)\end{array}$ & $\begin{array}{c}13.4 \pm 10.81 a \\
(10.5-15.9)\end{array}$ & 1.960 & .144 & .021 \\
\hline Grip strength (kg) & $\begin{array}{l}26.5 \pm 4.28 a \\
(25.5-27.6)\end{array}$ & $\begin{array}{l}26.0 \pm 4.30 a \\
(24.9-27.0)\end{array}$ & $\begin{array}{l}29.2 \pm 4.16 b \\
(28.2-30.2)\end{array}$ & 10.334 & .0001 & .101 \\
\hline Sit-ups (n) & $\begin{array}{r}13.2 \pm 9.43 a \\
(10.9-15.7)\end{array}$ & $\begin{array}{c}16.4 \pm 10.27 a \\
(13.9-18.9)\end{array}$ & $\begin{array}{l}21.3 \pm 9.21 b \\
(18.9-23.6)\end{array}$ & 11.059 & .0001 & .108 \\
\hline $\begin{array}{c}\mathrm{VO}_{2 m a x} \\
\left(\mathrm{ml} \cdot \mathrm{kg}^{-1} \cdot \mathrm{min}^{-1}\right)\end{array}$ & $\begin{array}{l}30.9 \pm 4.84 a \\
(29.7-32.2)\end{array}$ & $\begin{array}{l}31.1 \pm 4.86 a \\
(29.8-32.3)\end{array}$ & $\begin{array}{l}34.8 \pm 7.11 b \\
(32.9-36.6)\end{array}$ & 9.278 & .0001 & .092 \\
\hline $\begin{array}{c}\mathrm{HR}_{\max } \\
\left(\text { beats } \cdot \mathrm{min}^{-1} \text { ) }\right.\end{array}$ & $\begin{array}{r}173.5 \pm 10.64 a \\
(170.9-175.8)\end{array}$ & $\begin{array}{c}172.5 \pm 8.24 a \\
(170.2-174.5)\end{array}$ & $\begin{array}{l}174.6 \pm 10.33 a \\
(172.0-177.5)\end{array}$ & .718 & 0.489 & .008 \\
\hline
\end{tabular}

Note. Values are expressed as mean \pm standard deviation.

Different lowercase letters indicate significant differences among the groups

$95 \% \mathrm{Cl}, 95 \%$ confidence interval; VO2max, maximal oxygen uptake; HRmax, maximal heart rate

groups $\left(0.993 \pm 0.109 \mathrm{~g} / \mathrm{cm}^{2}\right)$.

\section{Health-related physical fitness}

Table 4 indicates the insignificant differences in SAR $\left(F=1.960, p=.114, \eta_{\mathrm{p}}{ }^{2}=.021\right)$ and HRmax $(F=.718, p=.489$, $\left.\eta_{\mathrm{p}}{ }^{2}=.008\right)$ among the three groups. However, significant differences were observed for GS $(F=10.334, p=.0001$, $\left.\eta_{\mathrm{p}}{ }^{2}=.101\right), \mathrm{SU}\left(F=11.059, p=.0001, \eta_{\mathrm{p}}{ }^{2}=.108\right)$, and $\mathrm{VO}_{2 \max }$ $\left(F=9.278, p=.0001, \eta_{\mathrm{p}}^{2}=.092\right)$ among the three groups. The high-score group had significantly higher GS (29.2 \pm 4.16 $\mathrm{kg})$, SU $(21.3 \pm 9.21 \mathrm{n})$, and $\mathrm{VO}_{2 \max }\left(34.8 \pm 7.11 \mathrm{ml} \cdot \mathrm{kg}^{-}\right.$ ${ }^{1} \cdot \mathrm{min}^{-1}$ ) than the middle- (GS, $26.0 \pm 4.30 \mathrm{~kg}$; SU, $16.4 \pm 10.27$ $\mathrm{n}$; $\left.\mathrm{VO}_{2 \max }, 31.1 \pm 4.86 \mathrm{ml} \cdot \mathrm{kg}^{-1} \cdot \mathrm{min}^{-1}\right)$ and low-score groups (GS, 26.5 $\pm 4.28 \mathrm{~kg} ; \mathrm{SU}, 13.2 \pm 9.43 \mathrm{n}$; $\mathrm{VO}_{2 \max }, 30.9 \pm 4.84$ $\left.\mathrm{ml} \cdot \mathrm{kg}^{-1} \cdot \mathrm{min}^{-1}\right)$.

\section{DISCUSSION}

The present study examined the effects of bone-specific PA on body composition, BMD, and health-related physical fitness in middle-aged women. This study revealed that bone-specific PA reduced percent body fat and increased FFM, whole-body BMD, lumbar BMD, GS, SU, and VO2 max.

It is well known that regular PA increases FFM and decreases percent body fat ${ }^{38}$. The results of this study showed that FFM in the high-score group was significantly higher than those in the middle- and low-score groups. Additionally, the high-score group showed a significantly lower percent body fat compared to the other two groups. These results are consistent with the results of the previous studies. Donnelly et al. ${ }^{39}$ reported that there was no difference in FM between women with a high PA level and a low PA level. Moreover, Thompson et al. ${ }^{40}$ reported that percent body fat in the high PA group was significantly lower than that in the low PA group in middle-aged women when measured by PA levels using the pedometer. Saravi and Sayegh ${ }^{18}$ reported that FFM in the habitual PA group was significantly higher than that in the sedentary group in premenopausal women when measured by PA levels using the IPAQ. Generally, participation in regular PA increases FFM and decreases percent body fat in mid- dle-aged premenopausal women, which helps in preventing obesity and sarcopenia. Therefore, regular PA is highly recommended to improve body composition.

A lifestyle change (e.g., regular participation in PA, nutrition intake, and cessation of smoking and alcohol intake) is an essential goal to prevent osteoporosis and fractures. The results of BMD in our study showed that whole-body $\mathrm{BMD}$ in the high-score group was significantly higher than that in the low-score group. Moreover, the high-score group showed significantly higher lumbar BMD compared to the other two groups. These results were consistent with the results of the previous studies, which confirmed that the high PA level had a positive impact on femur BMD and lumbar BMD $32,36,41$. Furthermore, it was stated that healthy young adults with a high PA level resulted in higher lumbar BMD and higher femur BMD ${ }^{42}$. Morseth et al. ${ }^{43}$ reported that a high PA level was closely associated with high femoral BMD in healthy female adults. Additionally, the comparison of BMD based on the PA level in middle-aged women showed that women with a high PA level had higher lumbar BMD, femur BMD, and whole-body BMD than women with a low PA level ${ }^{44-46}$. Ultimately, it was revealed that women who have a high PA level during adulthood had a low risk of osteoporosis during late adulthood $^{43,47}$. Therefore, to prevent osteopenia and osteoporosis and to restrain the rate of decrease in BMD with aging, it is necessary to participate in various physical activities, including high-impact exercise.

With aging, women's musculoskeletal fitness and cardiorespiratory endurance gradually decrease $\mathrm{e}^{48}$. However, participating in regular PA could improve musculoskeletal fitness, reducing the risk of chronic diseases and enhancing the overall health conditions ${ }^{49}$. The results of health-related physical fitness in this study showed that GS, SU, and $\mathrm{VO}_{2 \max }$ in the high-score group were significantly higher than those in the middle- and low-score groups. Based on a previous study, female adults with a high PA level showed higher $\mathrm{VO}_{2 \max }$ than female adults with a low PA level, and high cardiovascular endurance was positively associated with a high PA level ${ }^{50}$. Moreover, it was confirmed that the high PA level is positively associated with high physical fitness, which showed a beneficial effect on health conditions ${ }^{48}$. Therefore, participating in regular PA 
plays a vital role in improving health-related physical fitness and helps prevent musculoskeletal and cardiovascular diseases.

The present study revealed that a bone-specific PA reduced percent body fat and increased FFM, whole-body $\mathrm{BMD}$, lumbar BMD, GS, SU, and $\mathrm{VO}_{2 \max }$ in middle-aged women. We believe that a bone-specific PA could be useful in improving body composition, BMD, and health-related physical fitness in middle-aged women, ultimately enhancing their BMD and health conditions.

\section{ACKNOWLEDGMENT}

This work was supported by a grant from Kyung Hee University in 2018 (KHU-20180865).

\section{REFERENCES}

1. Kwan MY, Cairney J, Faulkner GE, Pullenayegum EE. Physical activity and other health-risk behaviors during the transition into early adulthood: a longitudinal cohort study. $A m \mathrm{~J}$ Prev Med. 2012;42:14-20.

2. Archer E, Blair SN. Physical activity and the prevention of cardiovascular disease: from evolution to epidemiology. Prog Cardiovasc Dis. 2011:53:387-96.

3. Sattelmair J, Pertman J, Ding EL, Kohl HW 3rd, Haskell W, Lee IM. Dose response between physical activity and risk of coronary heart disease: a meta-analysis. Circulation. 2011;124:789-95.

4. Smith SC Jr. Reducing the global burden of ischemic heart disease and stroke: a challenge for the cardiovascular community and the United Nations. Circulation. 2011;124:278-9.

5. Joseph P, Leong D, McKee M, Anand SS, Schwalm JD, Teo K, Mente A, Yusuf S. Reducing the Global Burden of Cardiovascular Disease, Part 1: The Epidemiology and Risk Factors. Circ Res. 2017;121:677-94.

6. Lozano R, Naghavi M, Foreman K, Lim S, Shibuya K, Aboyans V, Abraham J, Adair T, Aggarwal R, Ahn SY, Alvarado $M$, Anderson HR, Anderson LM, Andrews KG, Atkinson C Baddour LM, Barker-Collo S, Bartels DH, Bell ML, Benjamin EJ, Bennett D, Bhalla K, Bikbov B, Bin Abdulhak A, Birbeck G, Blyth F, Bolliger I, Boufous S, Bucello C, Burch M, Burney $\mathrm{P}$, Carapetis J, Chen H, Chou D, Chugh SS, Coffeng LE, Colan SD, Colquhoun S, Colson KE, Condon J, Connor MD, Cooper LT, Corriere M, Cortinovis M, de Vaccaro KC, Couser W, Cowie BC, Criqui MH, Cross M, Dabhadkar KC, Dahodwala N, De Leo D, Degenhardt L, Delossantos A, Denenberg J, Des Jarlais DC, Dharmaratne SD, Dorsey ER, Driscoll T, Duber H, Ebel B, Erwin PJ, Espindola P, Ezzati M, Feigin $\mathrm{V}$, Flaxman $A D$, Forouzanfar MH, Fowkes FG, Franklin R, Fransen M, Freeman MK, Gabriel SE, Gakidou E, Gaspari F, Gillum RF, Gonzalez-Medina D, Halasa YA, Haring D, Harrison JE, Havmoeller R, Hay RJ, Hoen B, Hotez PJ, Hoy $D$, Jacobsen $\mathrm{KH}$, James $\mathrm{SL}$, Jasrasaria $\mathrm{R}$, Jayaraman $\mathrm{S}$, Johns N, Karthikeyan G, Kassebaum N, Keren A, Khoo JP, Knowlton LM, Kobusingye O, Koranteng A, Krishnamurthi R,
Lipnick M, Lipshultz SE, Ohno SL, Mabweijano J, Maclntyre MF, Mallinger L, March L, Marks GB, Marks R, Matsumori A, Matzopoulos R, Mayosi BM, McAnulty JH, McDermott MM, McGrath J, Mensah GA, Merriman TR, Michaud C, Miller M, Miller TR, Mock C, Mocumbi AO, Mokdad AA, Moran A, Mulholland K, Nair MN, Naldi L, Narayan KM, Nasseri K, Norman P, O'Donnell M, Omer SB, Ortblad K, Osborne R, Ozgediz D, Pahari B, Pandian JD, Rivero AP, Padilla RP, Perez-Ruiz F, Perico N, Phillips D, Pierce K, Pope CA 3rd, Porrini E, Pourmalek F, Raju M, Ranganathan D, Rehm JT, Rein DB, Remuzzi G, Rivara FP, Roberts T, De León FR, Rosenfeld LC, Rushton L, Sacco RL, Salomon JA, Sampson U, Sanman E, Schwebel DC, Segui-Gomez M, Shepard DS, Singh D, Singleton J, Sliwa K, Smith E, Steer A, Taylor JA, Thomas B, Tleyjeh IM, Towbin JA, Truelsen T, Undurraga EA, Venketasubramanian N, Vijayakumar L, Vos T, Wagner GR, Wang M, Wang W, Watt K, Weinstock MA, Weintraub R, Wilkinson JD, Woolf AD, Wulf S, Yeh PH, Yip P, Zabetian A, Zheng ZJ, Lopez AD, Murray CJ, AlMazroa MA, Memish ZA. Global and regional mortality from 235 causes of death for 20 age groups in 1990 and 2010: a systematic analysis for the Global Burden of Disease Study 2010. Lancet. 2012;380:2095128.

7. Hu G, Jousilahti P, Borodulin K, Barengo NC, Lakka TA, Nissinen A, Tuomilehto J. Occupational, commuting and leisure-time physical activity in relation to coronary heart disease among middle-aged Finnish men and women. Atherosclerosis. 2007;194:490-7.

8. Li J, Siegrist J. Physical activity and risk of cardiovascular disease--a meta-analysis of prospective cohort studies. Int $J$ Environ Res Public Health. 2012;9:391-407.

9. Katzmarzyk PT, Gledhill N, Shephard RJ. The economic burden of physical inactivity in Canada. CMAJ. 2000;163:143540.

10. Colley RC, Garriguet D, Janssen I, Craig CL, Clarke J, Tremblay MS. Physical activity of Canadian adults: accelerometer results from the 2007 to 2009 Canadian Health Measures Survey. Health Rep. 2011;22:7-14.

11. Arikawa AY, O'Dougherty M, Kaufman BC, Schmitz KH, Kurzer MS. Attrition and adherence of young women to aerobic exercise: lessons from the WISER study. Contemp Clin Trials. 2012;33:298-301.

12. Barnett TA, Gauvin L, Craig CL, Katzmarzyk PT. Modifying effects of sex, age, and education on 22-year trajectory of leisure-time physical activity in a Canadian cohort. J Phys Act Health. 2007;4:153-66.

13. Sacheck JM, Kuder JF, Economos CD. Physical fitness, adiposity, and metabolic risk factors in young college students. Med Sci Sports Exerc. 2010;42:1039-44.

14. Yang L, Colditz GA. Prevalence of Overweight and Obesity in the United States, 2007-2012. JAMA Intern Med. 2015;175:1412-3.

15. Newman AB, Lee JS, Visser M, Goodpaster BH, Kritchevsky SB, Tylavsky FA, Nevitt M, Harris TB. Weight change and the conservation of lean mass in old age: the Health, Aging and Body Composition Study. Am J Clin Nutr. 2005;82:872-8.

16. Hughes VA, Frontera WR, Roubenoff R, Evans WJ, Singh MA. Longitudinal changes in body composition in older men 
and women: role of body weight change and physical activity. Am J Clin Nutr. 2002;76:473-81.

17. Maltais ML, Desroches J, Dionne IJ. Changes in muscle mass and strength after menopause. $J$ Musculoskelet Neuronal Interact. 2009;9:186-97.

18. Saravi FD, Sayegh F. Bone mineral density and body composition of adult premenopausal women with three levels of physical activity. J Osteoporos. 2013;2013:953271.

19. Ferrari S, Bianchi ML, Eisman JA, Foldes AJ, Adami S, Wahl DA, Stepan JJ, de Vernejoul MC, Kaufman JM; IOF Committee of Scientific Advisors Working Group on Osteoporosis Pathophysiology. Osteoporosis in young adults: pathophysiology, diagnosis, and management. Osteoporos Int. 2012;23:2735-48.

20. Baxter-Jones AD, Faulkner RA, Forwood MR, Mirwald $\mathrm{RL}$, Bailey DA. Bone mineral accrual from 8 to 30 years of age: an estimation of peak bone mass. $J$ Bone Miner Res. 2011;26:1729-39.

21. Camacho PM1, Dayal AS, Diaz JL, Nabhan FA, Agarwal M, Norton JG, Robinson PA, Albain KS. Prevalence of secondary causes of bone loss among breast cancer patients with osteopenia and osteoporosis. J Clin Oncol. 2008;26:5380-5.

22. Sui X, LaMonte MJ, Blair SN. Cardiorespiratory fitness as a predictor of nonfatal cardiovascular events in asymptomatic women and men. Am J Epidemiol. 2007;165:1413-23.

23. Newman AB, Kupelian V, Visser M, Simonsick EM, Goodpaster BH, Kritchevsky SB, Tylavsky FA, Rubin SM, Harris TB. Strength, but not muscle mass, is associated with mortality in the health, aging and body composition study cohort. $J$ Gerontol A Biol Sci Med Sci. 2006;61:72-7.

24. Gale CR, Martyn CN, Cooper C, Sayer AA. Grip strength, body composition, and mortality. Int J Epidemiol. 2007;36:228-35.

25. Riebe D, Blissmer BJ, Greaney ML, Garber CE, Lees FD, Clark PG. The relationship between obesity, physical activity, and physical function in older adults. $J$ Aging Health. 2009;21:1159-78.

26. Tuna HD, Edeer AO, Malkoc M, Aksakoglu G. Effect of age and physical activity level on functional fitness in older adults. Eur Rev Aging Phys Act. 2009;6:99.

27. Fleg JL, Morrell CH, Bos AG, Brant LJ, Talbot LA, Wright JG, Lakatta EG. Accelerated longitudinal decline of aerobic capacity in healthy older adults. Circulation. 2005;112:674-82.

28. Katzmarzyk PT, Church TS, Blair SN. Cardiorespiratory fitness attenuates the effects of the metabolic syndrome on all-cause and cardiovascular disease mortality in men. Arch Intern Med. 2004;164:1092-7.

29. Carnethon MR, Gidding SS, Nehgme R, Sidney S, Jacobs DR Jr, Liu K. Cardiorespiratory fitness in young adulthood and the development of cardiovascular disease risk factors. JAMA. 2003;290:3092-100.

30. Burtscher J, Ruedl G, Posch M, Greier K, Burtscher M. The upper limit of cardiorespiratory fitness associated with longevity: an update. AIMS Public Health. 2019;6:225-8.

31. Weeks BK, Beck BR. The BPAQ: a bone-specific physical activity assessment instrument. Osteoporos Int. 2008;19:156777.

32. Bolam KA, Beck BR, Adlard KN, Skinner TL, Cormie P, Gal- vão DA, Spry N, Newton RU, Taaffe DR. The relationship between BPAQ-derived physical activity and bone density of middle-aged and older men. Osteoporos Int. 2014;25:2663-8.

33. Rantalainen T, Weeks BK, Nogueira RC, Beck BR. Effects of bone-specific physical activity, gender and maturity on tibial cross-sectional bone material distribution: a cross-sectional pQCT comparison of children and young adults aged 5-29 years. Bone. 2015;72:101-8.

34. Kindler JM, Ross HL, Laing EM, Modlesky CM, Pollock NK, Baile CA, Lewis RD. Load-specific physical activity scores are related to tibia bone architecture. Int J Sport Nutr Exerc Metab. 2015;25:136-44.

35. Kim S, Baker BS, Sharma-Ghimire P, Bemben DA, Bemben MG. Association between bone-specific physical activity scores and $\mathrm{pQCT}$-derived measures of bone strength and geometry in healthy young and middle-aged premenopausal women. Arch Osteoporos. 2018;13:83.

36. Weeks BK, Purvis M, Beck BR. Physical activity estimated by the bone-specific physical activity questionnaire is also associated with cardiovascular risk. Eur J Sport Sci. 2016;16:1204-11.

37. Pescatello LS, Riebe D, Thompson PD. ACSM's guidelines for exercise testing and prescription. Lippincott Williams \& Wilkins. 2014.

38. Westerterp KR. Changes in physical activity over the lifespan: impact on body composition and sarcopenic obesity. Obes Rev. 2018;19 Suppl 1:8-13.

39. Donnelly JE, Hill JO, Jacobsen DJ, Potteiger J, Sullivan DK, Johnson SL, Heelan K, Hise M, Fennessey PV, Sonko B, Sharp T, Jakicic JM, Blair SN, Tran ZV, Mayo M, Gibson C, Washburn RA. Effects of a 16-month randomized controlled exercise trial on body weight and composition in young, overweight men and women: the Midwest Exercise Trial. Arch Intern Med. 2003;163:1343-50.

40. Thompson DL, Rakow J, Perdue SM. Relationship between accumulated walking and body composition in middle-aged women. Med Sci Sports Exerc. 2004;36:911-4.

41. Kim S, So WY, Kim J, Sung DJ. Relationship between Bone-Specific Physical Activity Scores and Measures for Body Composition and Bone Mineral Density in Healthy Young College Women. PloS One. 2016;11:e0162127.

42. Kemper HC, Twisk JW, van Mechelen W, Post GB, Roos JC, Lips P. A fifteen-year longitudinal study in young adults on the relation of physical activity and fitness with the development of the bone mass: The Amsterdam Growth And Health Longitudinal Study. Bone. 2000;27:847-53.

43. Morseth B, Emaus N, Wilsgaard T, Jacobsen BK, Jorgensen L. Leisure time physical activity in adulthood is positively associated with bone mineral density 22 years later. The Tromsø study. Eur J Epidemiol. 2010;25:325-31.

44. Hsu YH, Venners SA, Terwedow HA, Feng Y, Niu T, Li Z, Laird N, Brain JD, Cummings SR, Bouxsein ML, Rosen CJ, $\mathrm{Xu}$ X. Relation of body composition, fat mass, and serum lipids to osteoporotic fractures and bone mineral density in Chinese men and women. Am J Clin Nutr. 2006;83:146-54.

45. Kelley $\mathrm{G}$. Aerobic exercise and lumbar spine bone mineral density in postmenopausal women: a meta-analysis. $\mathrm{J} \mathrm{Am}$ Geriatr Soc. 1998;46:143-52. 
46. Kelley GA. Aerobic exercise and bone density at the hip in postmenopausal women: a meta-analysis. Prev Med. 1998;27:798-807.

47. Ilich-Ernst J, Brownbill RA, Ludemann MA, Fu R. Critical factors for bone health in women across the age span: how important is muscle mass? Medscape Womens Health. 2002;7:2.

48. Blair SN, Cheng Y, Holder JS. Is physical activity or physical fitness more important in defining health benefits? Med Sci Sports Exerc. 2001;33:S379-99.

49. Warburton DER, Bredin SSD. Health Benefits of Physical Activity: A Strengths-Based Approach. J Clin Med. 2019;8:2044.

50. Church TS, Earnest CP, Skinner JS, Blair SN. Effects of different doses of physical activity on cardiorespiratory fitness among sedentary, overweight or obese postmenopausal women with elevated blood pressure: a randomized controlled trial. JAMA. 2007;297:2081-91. 